Marquette University

e-Publications@Marquette

College of Nursing Faculty Research and

Publications

Nursing, College of

$9-2-2021$

\title{
Examining the Course of Transitions from Hospital to Home- based Palliative Care: A Mixed Methods Study
}

\author{
Stephanie Saunders \\ McMaster University \\ Marianne Weiss \\ Marquette University, marianne.weiss@marquette.edu \\ Chris Meaney \\ University of Toronto \\ Tieghan Killackey \\ University of Toronto \\ Jaymie Varenbut \\ Temmy Latner Centre for Palliative Care
}

See next page for additional authors

Follow this and additional works at: https://epublications.marquette.edu/nursing_fac

Part of the Nursing Commons

\section{Recommended Citation}

Saunders, Stephanie; Weiss, Marianne; Meaney, Chris; Killackey, Tieghan; Varenbut, Jaymie; Lovrics, Emily; Ernecoff, Natalie; Hsu, Amy T.; Stern, Maya; Mahtani, Ramona; Wentlandt, Kirsten; and Isenberg, Sarina R., "Examining the Course of Transitions from Hospital to Home-based Palliative Care: A Mixed Methods Study" (2021). College of Nursing Faculty Research and Publications. 896.

https://epublications.marquette.edu/nursing_fac/896 


\section{Authors}

Stephanie Saunders, Marianne Weiss, Chris Meaney, Tieghan Killackey, Jaymie Varenbut, Emily Lovrics, Natalie Ernecoff, Amy T. Hsu, Maya Stern, Ramona Mahtani, Kirsten Wentlandt, and Sarina R. Isenberg 
Marquette University

e-Publications@Marquette

\section{Nursing Faculty Research and Publications/College of Nursing}

This paper is NOT THE PUBLISHED VERSION.

Access the published version via the link in the citation below.

Palliative Medicine, Vol. 35, No. 8 (September 2, 2021): 1590-1601. DOI. This article is (C SAGE

Publications and permission has been granted for this version to appear in e-Publications@Marquette. SAGE Publications does not grant permission for this article to be further copied/distributed or hosted elsewhere without the express permission from SAGE Publications.

\section{Examining the Course of Transitions from Hospital to Home-based Palliative Care: A Mixed Methods Study}

Stephanie Saunders

Rehabilitation Sciences, Faculty of Health Sciences, McMaster University, Hamilton, ON, Canada

Marianne E. Weiss

Marquette University College of Nursing, Milwaukee, WI, USA

Chris Meaney

Department of Family \& Community Medicine, University of Toronto, Toronto, ON, Canada

Tieghan Killackey

Lawrence S. Bloomberg Faculty of Nursing, University of Toronto, Toronto, ON, Canada

Jaymie Varenbut

Temmy Latner Centre for Palliative Care, Sinai Health, Toronto, ON, Canada

Emily Lovrics

Temmy Latner Centre for Palliative Care, Sinai Health, Toronto, ON, Canada

Natalie Ernecoff

Division of General Internal Medi ine, University of Pittsburgh School of Medicine, Pittsburgh, PA, USA 


\author{
Amy T. Hsu \\ Bruyère Research Institute, Ottawa, $\mathrm{ON}$, Canada \\ Ottawa Hospital Research Institute, Ottawa, ON, Canada \\ Maya Stern \\ Patient Advocate, Toronto, ON, Canada \\ Ramona Mahtani \\ Department of Family \& Community Medicine, University of Toronto, Toronto, ON, Canada \\ Temmy Latner Centre for Palliative Care, Sinai Health, Toronto, ON, Canada \\ Kirsten Wentlandt \\ Division of Palliative Care, University Health Network, Toronto, ON, Canada \\ Sarina R. Isenberg \\ Department of Family \& Community Medicine, University of Toronto, Toronto, ON, Canada \\ Bruyère Research Institute, Ottawa, ON, Canada
}

\title{
Abstract \\ Background:
}

Hospital-to-home transitions in palliative care are fraught with challenges. To assess transitions researchers have used patient reported outcome measures and qualitative data to give unique insights into a phenomenon. Few measures examine care setting transitions in palliative care, yet domains identified in other populations are likely relevant for patients receiving palliative care.

Aim:

Gain insight into how patients experience three domains, discharge readiness, transition quality, and dischargecoping, during hospital-to-home transitions.

Design:

Longitudinal, convergent parallel mixed methods study design with two data collection visits: in-hospital before and 3-4 weeks after discharge. Participants completed scales assessing discharge readiness, transition quality, and post discharge-coping. A qualitative interview was conducted at both visits. Data were analyzed separately and integrated using a merged transformative methodology, allowing us to compare and contrast the data.

\section{Setting and participants:}

Study was set in two tertiary hospitals in Toronto, Canada. Adult inpatients $(n=25)$ and their caregivers $(n=14)$ were eligible if they received a palliative care consultation and transitioned to home-based palliative care.

\section{Results:}

Results were organized aligning with the scales; finding low discharge readiness (5.8; IQR: 1.9), moderate transition quality (66.7; IQR: 33.33), and poor discharge-coping (5.0; IQR: 2.6), respectively. Positive transitions involved feeling well supported, managing medications, feeling well, and having healthcare needs met. Challenges in transitions were feeling unwell, confusion over medications, unclear healthcare responsibilities, and emotional distress. 


\section{Conclusions:}

We identified aspects of these three domains that may be targeted to improve transitions through intervention development. Identified discrepancies between the data types should be considered for future research exploration.

\section{Keywords}

Palliative care, discharge readiness, mixed methods, home care services, transitions, post-discharge coping, patient discharge

\section{What is already known about the topic?}

- Transitions between care settings can be fraught with challenges.

- As a result of the desire to spend end of life at home, a common transition for palliative care patients is from the hospital to the home.

- Researchers have used qualitative methods to assess transitions, identifying challenges in continuity of care, collaboration, and logistics.

- Patient reported outcome measures (PROMs) and patient reported experience measures (PREMs) can add patient and family member voices to evaluations of care quality and their transition experience.

- There are few measures that assess these care setting transitions in patients receiving palliative care, yet domains identified in other populations are likely relevant for palliative patients.

\section{What the paper adds?}

- By using a mixed methods study design, the two data types offer complementary insights; the PROM/PREM findings provide structure for better understanding three domains of a transition, whereas the qualitative insights offer explanations and reasons for why or how these findings occur.

- Positive transitions were characterized by feeling well supported, managing medications, feeling well, and having healthcare needs met.

- Challenging transitions involved feeling unwell, confusion over medications, not understanding their health-related responsibilities, and emotional distress.

- By identifying discrepancies between the qualitative and quantitative data, we found that PROM/PREM outcomes may have been affected by participants' eagerness to go home, not having healthcare needs met, and unexpected reduced capacity once home.

\section{Implications for practice, theory, or policy?}

- For each domain of the transition from hospital to home (i.e. discharge readiness, transition quality, and post-discharge coping), the agreement between the qualitative and quantitative data, for both positive and negative outcomes, suggests areas that are clearly important to palliative care patients and/or caregivers in transitions that future interventions can aim to address.

- The identified discrepancies between qualitative and quantitative data indicate areas for future exploration.

\section{Introduction}

Transitions of care, the coordinated movement of patients between different healthcare settings, healthcare providers, or intensity of care, ${ }^{1,2}$ are critical junctures in patients' care trajectories. During transitions, patients and caregivers may experience challenges including disruption in care plans, lack of communication, uncertainty, 
and safety concerns. ${ }^{1-4}$ From a health system perspective, poor transitions can lead to greater health service use, increased likelihood of 30-day readmissions, and higher healthcare spending. ${ }^{4}$

To understand transitions, researchers have developed various validated patient-reported outcome measures (PROMs) and patient reported experience measures (PREMs). ${ }^{5}$ PROMs/PREMs support patient-centered care and enable the assessment of quality of care over time. ${ }^{6,7}$ Multiple reviews have synthesized domains of care transitions, with measures to identify patient safety during a transition, ${ }^{2,6,8}$ coordination of care, ${ }^{9,10}$ quality of the transition, ${ }^{11-13}$ and continuity of care. ${ }^{10,12}$ Yet, few of these assess a transition in care settings, and none assess these in patients receiving palliative care. As a result, the literature in palliative transitions focuses on the impact of palliative care on health service utilization; assessing discharge support, readmissions, and costs. ${ }^{14,15}$ This focus overlooks qualitative findings highlighting the importance of continuity of care, coordination and collaboration, and clear logistic support. ${ }^{16,17}$

Palliative patients are likely to experience many transitions in care settings because of their serious conditions, ${ }^{18}$ a common one being from hospital-to-home. ${ }^{19-22}$ The lack of validated PROMs/PREMs makes measurement of transition outcomes difficult in this population. Validated measures have been developed for other populations to capture domains of transitions relevant to hospital-to-home transitions, namely discharge readiness, transition quality, and post-discharge coping. ${ }^{23,24}$ While these domains are likely relevant for transitions in palliative care patients, determining the applicability and experience within palliative care will provide valuable inputs for future service enhancements. To this end, we adopted a mixed methods approach to develop insight into how palliative patients experience these three domains during hospital-to-home transitions.

\section{Methods}

\section{Research question}

How do palliative care patients and/or caregivers experiences of discharge readiness, transition quality, and discharge coping impact their hospital-to-home transition?

\section{Study design}

Using a convergent, parallel mixed methods study design ${ }^{25,26}$ we evaluated the transition experience. ${ }^{27}$ Mixed methods are designed to offset methodological limitations by offering distinct yet overlapping data that can be used to contextualize and corroborate findings. We made use of a pragmatic approach, ${ }^{25}$ which facilitates weaving together two contrasting and inherently different methodologies by accepting "singular and multiple realities" open to interpretation. Our qualitative and quantitative data were collected concurrently, analyzed separately, and integrated to give insight into the hospital-to-home transition. ${ }^{28}$

\section{Setting/population}

Potentially eligible patients: (1) were at least 18 years of age; (2) had a Palliative Performance Scale score $\geqslant 30 \%{ }^{29}(3)$ received palliative care from an inpatient consultation service at one of two tertiary hospitals (Toronto General Hospital and Mount Sinai Hospital) located in Toronto, Canada; (4) were referred to a homebased palliative care program; (5) were fluent in English; and (6) had capacity for consent. We included caregivers fluent in English with the capacity to consent. In some circumstances the patient and caregiver participated as a dyad and if the patient was unable, the caregiver participated alone.

\section{Sampling}

We made use of a purposive sampling strategy, wherein we intentionally selected participants who would be able to speak to the hospital-to-home transition. Given that we only examined descriptive statistics of the quantitative data, we sampled patients until we had achieved theoretical saturation in our qualitative data. 


\section{Recruitment}

Saturation was indicated by recurring themes in the data through ongoing analysis during recruitment. Potential participants were identified twice-weekly by the palliative care consultation team. Individuals were approached by study staff, informed of the study, and provided written consent to participate.

\section{Data collection}

Study staff visited participants for data collection on two occasions from October 2018 to 2019. Visit 1 occurred in the hospital up to 4 days prior to the patient being discharged home. Visit 2 occurred once the patient was home and had been seen by the palliative care physician, approximately 1 month after discharge. Data collection occurred in the same order for each participant; first completing the quantitative surveys, then completing the qualitative interview.

\section{Quantitative data}

The patient and/or caregiver were asked to complete three scales. The PROM scales were: Readiness for Hospital Discharge Scale (RHDS, where lower scores imply low readiness) ${ }^{24}$ and Post-Discharge Coping Difficulty Scale (PDCDS, where higher scores imply a poor transition). ${ }^{13}$ The PREM scale was the Care Transitions Measure3 item (CTM-3, where lower scores imply a low quality transition). ${ }^{30}$ These scales have been widely used in discharge transition research. Detailed descriptions and evidence of reliability and validity in adult medical surgical patients are included in Table 1. A demographic survey was completed at the first visit. If the patient felt unable to complete the scales, the caregiver completed patients' demographic data on their behalf and completed the scales reporting their own perceptions of the patient transition. 
Table 1. Description of data collection.

\begin{tabular}{|c|c|c|c|c|c|}
\hline $\begin{array}{l}\text { Survey } \\
\text { Type }\end{array}$ & $\begin{array}{l}\text { Name of data } \\
\text { collection } \\
\text { tools }\end{array}$ & Description and parameters & $\begin{array}{l}\text { Validated } \\
\text { population (if } \\
\text { applicable) }\end{array}$ & Sample Questions & $\begin{array}{l}\text { Time } \\
\text { point } \\
\text { collected }\end{array}$ \\
\hline NA & $\begin{array}{l}\text { Patient } \\
\text { information } \\
\text { form }\end{array}$ & $\begin{array}{l}\text { Purpose: a questionnaire asking for sociodemographic } \\
\text { background and health history } \\
\text { Item count: } 7 \\
\text { Score range: NA } \\
\text { Interpretation: NA } \\
\text { Dichotomy calculation: NA }\end{array}$ & NA & $\begin{array}{l}\text { "What is your age" } \\
\text { "What is your gender" } \\
\text { "What is your highest } \\
\text { education level" } \\
\text { "Which best describes your } \\
\text { racial or ethnic group" } \\
\text { "What is your religious or } \\
\text { spiritual affiliation" }\end{array}$ & Visit 1 \\
\hline PROM & $\begin{array}{l}\text { Readiness for } \\
\text { Hospital } \\
\text { Discharge } \\
\text { Scale } \\
\text { (RHDS)13 }\end{array}$ & $\begin{array}{l}\text { Purpose: measures patient or caregiver readiness to be } \\
\text { discharged from the hospital } \\
\text { Item count: } 8 \text { items } \\
\text { Score range: } 0-10 ; \text { scores are reported using the } \\
\text { summated item mean } \\
\text { Interpretation: lower scores indicate lower quality } \\
\text { transition; higher scores indicate greater readiness for } \\
\text { discharge } \\
\text { Reliability: Cronbach alpha: } 0.89 \\
\text { Construct validity: factor loading between } 0.67 \text { and } 0.84 \\
\text { Dichotomy calculation: scores < empirical median } \\
\text { indicates low readiness and scores } \geq \text { median indicate high } \\
\text { readiness; this scoring was also used for caregivers }\end{array}$ & $\begin{array}{l}\text { Adult medical- } \\
\text { surgical } \\
\text { patients; } \\
\text { postpartum } \\
\text { mothers; parents } \\
\text { of } \\
\text { hospitalized } \\
\text { patients }\end{array}$ & & \\
\hline PREM & $\begin{array}{l}\text { Care } \\
\text { Transitions } \\
\text { Measure-3 } \\
\text { (CTM-3)30 }\end{array}$ & $\begin{array}{l}\text { Purpose: measure to determine the quality of the } \\
\text { transition as experienced by patients; we modified this } \\
\text { measure to be completed by caregivers if necessary, } \\
\text { which has been done in the past } \\
\text { Item count: } 3 \text { items } \\
\text { Score range: } 1-4 \text { (strongly disagree, disagree, agree, } \\
\text { strongly agree); of which the mean score is linearly } \\
\text { transformed to a } 0-100 \text { scale } \\
\text { Interpretation: lower scores indicate lower quality } \\
\text { transition; higher scores indicate better quality transition }\end{array}$ & $\begin{array}{l}\text { Patients } \geq 65 \text { and } \\
\text { had been } \\
\text { admitted to the } \\
\text { hospital } \\
\text { at least once in } \\
\text { the past } \\
\text { 12-months and } \\
\text { was receiving } \\
\text { either homecare } \\
\text { or care }\end{array}$ & $\begin{array}{l}\text { "When I left the hospital, I } \\
\text { clearly understood the purpose } \\
\text { for taking each of } \\
\text { my medications" }\end{array}$ & Visit 2 \\
\hline
\end{tabular}




\begin{tabular}{|c|c|c|c|c|c|}
\hline & & $\begin{array}{l}\text { Reliability: cronbach alpha in the } 15 \text {-item measure ranged } \\
\text { from } 0.93 \text { to } 0.96 \\
\text { Criterion validity: as compared to the } 15 \text {-item CTM, the 3- } \\
\text { items predicted } 88 \% \text { of the adjusted variance } \\
(\mathrm{F}=528.65) \\
\text { Dichotomy calculation: scores }<\text { empirical median } \\
\text { indicates low quality and scores } \geq \text { median indicate high } \\
\text { quality; this scoring was also used for caregivers }\end{array}$ & $\begin{array}{l}\text { from a skilled } \\
\text { nursing facility; } \\
\text { Hospitalized } \\
\text { patients who fit } \\
\text { one of three } \\
\text { demographics: } \\
\text { (1) African } \\
\text { American, (2) } \\
\text { Hispanic } \\
\text { American, or (3) } \\
\text { rural-dwelling }\end{array}$ & & \\
\hline PROM & $\begin{array}{l}\text { Post- } \\
\text { discharge } \\
\text { coping } \\
\text { difficulty } \\
\text { scale } \\
\text { (PDCDS)13 }\end{array}$ & $\begin{array}{l}\text { Purpose: a questionnaire asking for sociodemographic } \\
\text { background and health history } \\
\text { Item count: } 11 \text { items } \\
\text { Score range: } 0-10 ; \text { scores are reported using the } \\
\text { summated item mean } \\
\text { Interpretation: a low score indicates an easier time coping } \\
\text { at home and high score indicates a more difficult } \\
\text { time coping post-discharge } \\
\text { Reliability: Cronbach alpha: } 0.82 \\
\text { Construct validity: factor analysis indicated a single } \\
\text { dominant factor accounted for } 39 \% \text { of the variance } \\
\text { Dichotomy calculation: scores }<\text { empirical median } \\
\text { indicates lower difficulty and scores } \geq \text { median indicate } \\
\text { higher difficulty; this scoring was also used for caregivers }\end{array}$ & $\begin{array}{l}\text { Adult medical- } \\
\text { surgical } \\
\text { patients; } \\
\text { postpartum } \\
\text { mothers; parents } \\
\text { of } \\
\text { hospitalized } \\
\text { patients }\end{array}$ & $\begin{array}{l}\text { "Since you've been home how } \\
\text { much difficulty have you had } \\
\text { with caring for } \\
\text { yourself?" }\end{array}$ & Visit 2 \\
\hline NA & $\begin{array}{l}\text { Interview } \\
\text { guide }\end{array}$ & $\begin{array}{l}\text { Purpose: a semi-structured interview guide that began } \\
\text { with broad questions and consisted of prompts for } \\
\text { follow-up questions based on participants answers } \\
\text { Item count: } 20 \text { direct questions were in the interview } \\
\text { guide, however probing questions were asked to clarify } \\
\text { and obtain deeper insights into answers } \\
\text { Score range: NA } \\
\text { Interpretation: NA } \\
\text { Dichotomy calculation: Transcript } 1 \text { was designated high } \\
\text { readiness for discharge when the codes mapped to } \\
\text { the RHDS were discussed in a positive light, or they had a } \\
\text { positive experience not captured in the RHDS codes; }\end{array}$ & NA & $\begin{array}{l}\text { Visit 1: } \\
\text { "How long have you been } \\
\text { here? Do you expect to go } \\
\text { home soon?" } \\
\text { "Can you tell me a bit about } \\
\text { what you expect a normal day } \\
\text { to look like when } \\
\text { you get home?" } \\
\text { "Can you tell me about what } \\
\text { kind of care has been set up to } \\
\text { help you out } \\
\text { at home?" }\end{array}$ & $\begin{array}{l}\text { Visit } 1 \\
\text { and } \\
\text { Visit } 2\end{array}$ \\
\hline
\end{tabular}




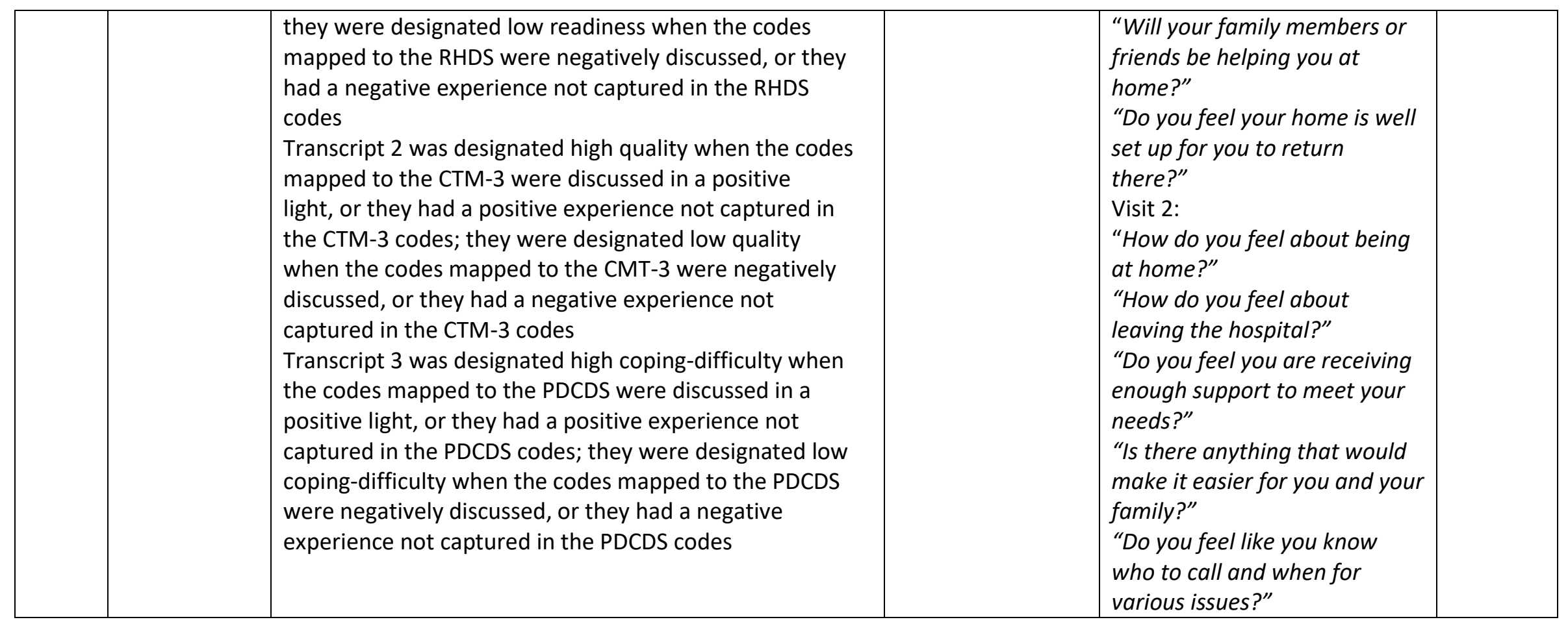

NA; not applicable. 
Qualitative data

Our method of inquiry was based in grounded theory, wherein we systematically and intentionally collected and reviewed qualitative data. Semi-structured interviews were conducted after completing the scales in the hospital (Visit 1) and in the home (Visit 2) by SRI, JV, and SS. Interview questions were co-created with the research team and patient advocate (MS). The questions explored expectations and the experience of hospitalto- home transitions (see Table 1). All interviewers had past qualitative research experience and mock interviews were conducted with a patient advocate (MS) prior to commencing the study. Dyads were interviewed together. All interviews were conducted in-person, audio recorded, and transcribed verbatim.

\section{Data analysis}

Consistent with convergent parallel design, we analyzed the quantitative and qualitative data independently and then integrated our findings.

\section{Quantitative data}

We presented descriptive statistics on survey scores, then dichotomized participants into binary high or low levels for each of the scales based on the median to prepare for comparisons of survey and interview data. For details on this process see Table 1.

\section{Qualitative data}

The initial codes were developed inductively through grounded theory approach (see Isenberg et al., ${ }^{31}$ for more details). Transcripts were analyzed and coded throughout the interview process by a minimum of two reviewers (SS, SRI, TK) using MaxQDA data analysis software; ${ }^{32}$ disagreement was resolved through discussion.

\section{Integration}

To integrate our data we made use of a merged transformative methodology, ${ }^{25,33}$ where our qualitative data was transformed to quantitative (i.e. dichotomous) variables for comparison. To transform the qualitative data we mapped the developed codes onto the scale concepts. The qualitative data were then compared to the scale items using the MaxQDA crosstabs function and by examining the codes and in vivo quotes of each participant independent of the quantitative scores (SS). Each Visit 1 transcript was summarized as high or low discharge readiness and Visit 2 transcripts were summarized as high or low quality of transition and post-discharge coping difficulty ((SS) see Table 1). For unclear designations, a second reviewer was consulted (SRI).

Once translated into dichotomized components, we manually and statistically compared the data. For this portion of the analyses, we used caregiver scores when patients were not able to directly respond, to represent the experience of the patient/caregiver dyad in the discharge transition. The manual comparison involved examining the data for similarities and contradictions, which offered rich detailed understanding of the transitions phenomena as a whole. Further, we statistically compared the scales to the qualitative data using a kappa agreement coefficient (scores $\leqslant 0=$ poor, $0.01-0.20=$ slight, $0.21-0.40=$ fair, $0.41-0.60=$ moderate, $0.61-$ $0.80=$ substantial, and $0.81-1=$ almost perfect $).{ }^{34}$ This process provides context and rigor for readers.

\section{Ethical issues}

All participants were consented following institutional approval at the University Health Network and Sinai Health (REB\#18-5686 and \#18-0172-E respectively).

\section{Results}

Seventy eligible patients were approached for the study. From this, 39 participants engaged in Visit 1 of the study, of whom 25 were patients, 7 were family caregivers of patients unable to respond to study surveys and/or interview, and 7 caregivers participated in a dyad interview (see Figure 1). Twenty-three participants 
took part in both visits. Interviews were on average $29 \mathrm{~min}$, with a range of 7-80 min. Patient characteristics are described in Table 2(a) and (b). Qualitatively themes are integrated with quantitative findings in the narrative presentation of results. Table 3 presents the summary quantitative descriptive results; Table 4 presents the crosstabulation of quantitative findings with dichotomized qualitative findings.

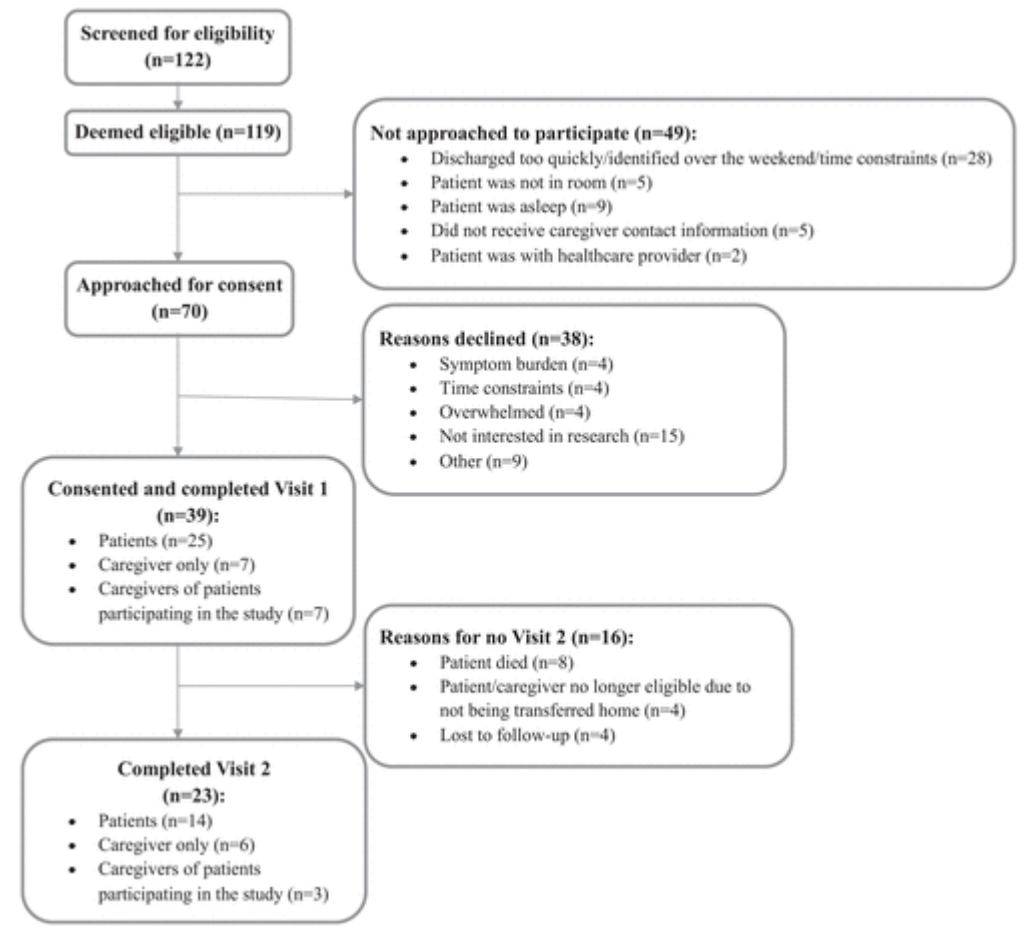

Figure 1. Recruitment flow chart. 
Table 2a. Demographics of patients and caregivers.

\begin{tabular}{|c|c|c|}
\hline Characteristics & Patients $(N=25)$ & Caregivers $(N=14)$ \\
\hline Age in years, median (IQR) & $68(58-77)$ & $62(50.25-73.5)$ \\
\hline Female sex, $n(\%)$ & $15(60)$ & $7(50)$ \\
\hline Completion of post-secondary education, $n(\%)$ & $17(68)$ & $9(64)$ \\
\hline \multicolumn{3}{|l|}{ Racial or ethnic group, $n(\%)$} \\
\hline White & $19(76)$ & $8(57)$ \\
\hline Asian & $4(16)$ & $3(21)$ \\
\hline Black & $1(4)$ & $2(14)$ \\
\hline Other & $1(4)$ & $1(7)$ \\
\hline \multicolumn{3}{|l|}{ Religious or spiritual affiliation $n(\%)$} \\
\hline Christianity/Roman Catholic & $10(40)$ & $7(50)$ \\
\hline No religious/spiritual affiliation/atheism & $7(28)$ & $3(21)$ \\
\hline Other1 & $8(32)$ & $4(29)$ \\
\hline \multicolumn{3}{|l|}{ Number of comorbidities, $n(\%)^{2}$} \\
\hline 0 & 0 & $5(36)$ \\
\hline 1 & $7(22)$ & $3(21)$ \\
\hline 2 & $9(28)$ & $4(29)$ \\
\hline$\geq 3$ & $16(50)$ & $2(14)$ \\
\hline \multicolumn{3}{|l|}{ Confidence in filling out medical forms by oneself, $n$ (\%) } \\
\hline Extremely/quite a bit & $23(92)$ & $13(93)$ \\
\hline Somewhat/a little bit/not at all & $2(8)$ & $1(7)$ \\
\hline \multicolumn{3}{|l|}{ Relationship to the patient, $n(\%)$} \\
\hline Child & $\mathrm{N} / \mathrm{A}$ & $4(29)$ \\
\hline Parent & $\mathrm{N} / \mathrm{A}$ & $2(14)$ \\
\hline Spouse (married or common law) & $\mathrm{N} / \mathrm{A}$ & $6(43)$ \\
\hline Other & $\mathrm{N} / \mathrm{A}$ & $2(14)$ \\
\hline \multicolumn{3}{|l|}{ Role with the patient, $n(\%)$} \\
\hline $\begin{array}{l}\text { I provide assistance with physical activities that occur during the course of the day (e.g. feeding, } \\
\text { toileting, bathing, dressing, grooming, maintaining continence, walking, and homemaking) }\end{array}$ & $\mathrm{N} / \mathrm{A}$ & $10(71)$ \\
\hline $\begin{array}{l}\text { I provide assistance in helping accomplish specific tasks (e.g. managing finances, driving or navigating } \\
\text { public transit to and from appointments and errands, shopping, preparing meals, using the telephone } \\
\text { and other communication devices, managing medications, housework, and basic home maintenance) }\end{array}$ & $\mathrm{N} / \mathrm{A}$ & $14(100)$ \\
\hline
\end{tabular}




\begin{tabular}{|c|c|c|}
\hline $\begin{array}{l}\text { I provide emotional support (e.g. listening, talking, reading, playing music, providing caring } \\
\text { companionship and love) }\end{array}$ & $\mathrm{N} / \mathrm{A}$ & $14(100)$ \\
\hline I accompany the patient to religious/spiritual services or events & N/A & $7(50)$ \\
\hline I accompany the patient to medical appointments and procedures & N/A & $14(100)$ \\
\hline I participate in discussions about treatment in medical appointments and procedures & N/A & $14(100)$ \\
\hline I monitor symptoms and changes in health status & N/A & $14(100)$ \\
\hline I am the patient's medical decision maker and/or I am his/her healthcare power of attorney & N/A & $11(79)$ \\
\hline Other & $\mathrm{N} / \mathrm{A}$ & $2(14)$ \\
\hline Live in the same residence as the patient, $n(\%)$ & N/A & $11(79)$ \\
\hline
\end{tabular}

${ }^{1}$ Participants did not identify with any additional religious/spiritual affiliations.

${ }^{2}$ Based on self-reported data.

Table $\mathbf{2 b}$. Clinical characteristics of patients affiliated with the study.

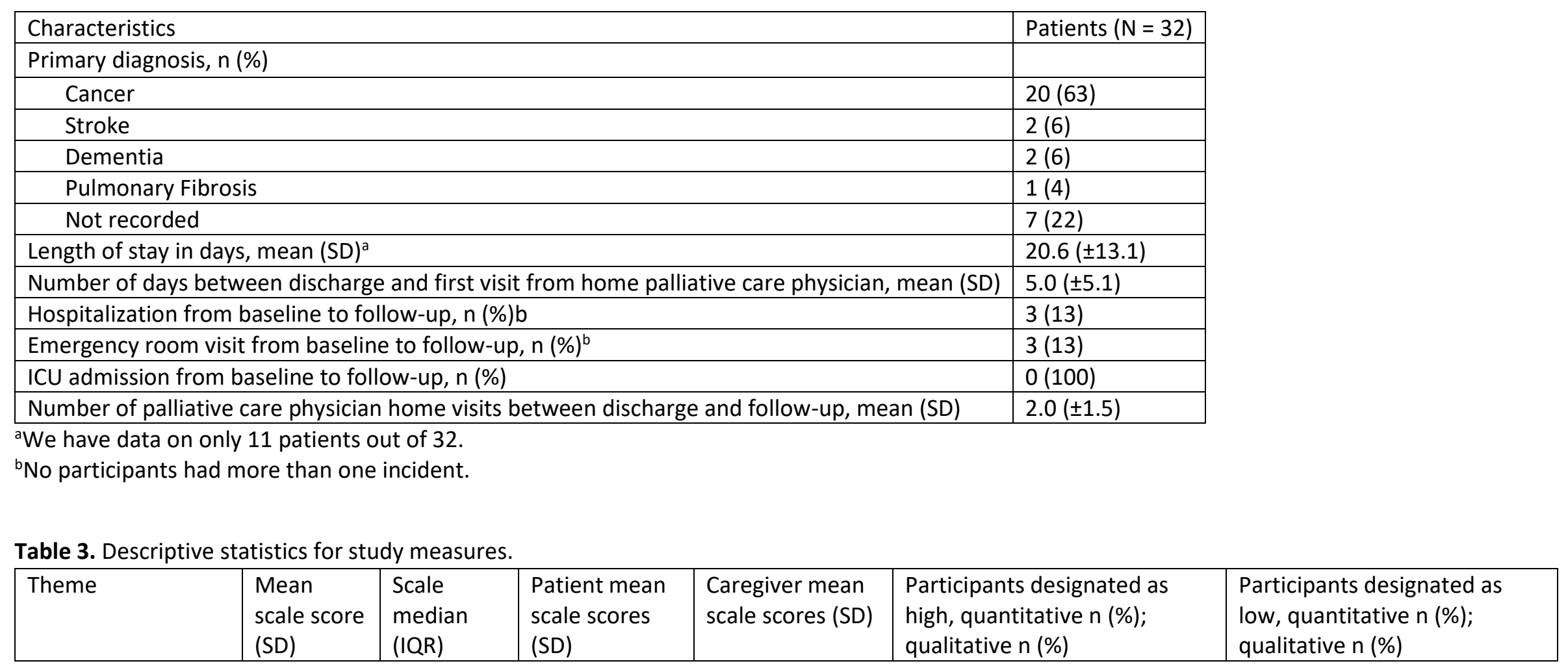




\begin{tabular}{|l|l|l|l|l|l|l|}
\hline $\begin{array}{l}\text { Readiness for } \\
\text { hospital discharge, } \\
\mathrm{N}=32\end{array}$ & $6.1(1.4)$ & $5.8(1.9)$ & $6.1(1.5)$ & $6.1(1.3)$ & $15(47) ; 13(42)$ & $17(53) ; 18(58)$ \\
\hline $\begin{array}{l}\text { Quality of } \\
\text { transition, N = 20 }\end{array}$ & $67.3(23.3)$ & $\begin{array}{l}66.7 \\
(33.33)\end{array}$ & $65.9(22)$ & $75.9(28.4)$ & $9(45) ; 9(45)$ & $11(55) ; 11(55)$ \\
\hline $\begin{array}{l}\text { Post-discharge } \\
\text { coping difficulty, N } \\
=20\end{array}$ & $5.1(1.9)$ & $5.0(2.6)$ & $4.0(1.3)$ & $6.8(1.4)$ & $10(50) ; 10(50)$ & $10(50) ; 10(50)$ \\
\hline
\end{tabular}

Table 4. Concordance between qualitative data and quantitative scales.

\begin{tabular}{|c|c|c|c|c|c|c|}
\hline Themes & $\begin{array}{l}\text { Qualitative } \\
\text { low versus } \\
\text { quantitative low }\end{array}$ & $\begin{array}{l}\text { Qualitative } \\
\text { low versus } \\
\text { quantitative }\end{array}$ & $\begin{array}{l}\text { Qualitative } \\
\text { high versus } \\
\text { quantitative }\end{array}$ & $\begin{array}{l}\text { Quantitative } \\
\text { high versus } \\
\text { qualitative }\end{array}$ & $\begin{array}{l}\text { Raw agreement } \\
\text { (proportion) } \\
(95 \% \mathrm{Cl})\end{array}$ & $\begin{array}{l}\text { Kappa-chance } \\
\text { corrected agreement } \\
\text { (proportion) }(95 \% \mathrm{Cl})\end{array}$ \\
\hline & $n(\%)$ & high $n(\%)$ & low $n(\%)$ & high n (\%) & & \\
\hline Readiness for hospital discharge & $11(35)$ & $7(23)$ & $6(19)$ & $7(23)$ & $0.58(0.39,0.76)$ & $0.15(-0.20,0.50)$ \\
\hline Quality of transitions & $7(35)$ & $4(20)$ & $4(20)$ & $5(25)$ & $0.60(0.36,0.81)$ & $0.19(-0.24,0.62)$ \\
\hline Post-discharge coping difficulty & $7(35)$ & $3(15)$ & $3(15)$ & $7(35)$ & $0.65(0.41,0.85)$ & $0.30(-0.12,0.72)$ \\
\hline
\end{tabular}




\section{Readiness for discharge}

The median score of the RHDS data was 5.8 (IQR, 1.9), with $47 \%$ categorized as high readiness and $53 \%$ indicating low readiness. This contrasted slightly with our qualitative data, with $42 \%$ expressing high readiness, and $58 \%$ expressing low readiness for discharge. The chance corrected kappa score was $0.15(95 \% \mathrm{Cl}:-0.20$, $0.50)$.

Those who indicated they had high readiness in both their qualitative and RHDS data $(n=7,23 \%)$ felt they knew how to perform care tasks at home, had sufficient community support, and believed administrative issues delayed their discharge from hospital. A patient described this experience saying: "The biggest challenge I've had is being told several different discharge dates and they don't happen. Not necessarily because there's medical issues, but administrative" (Female patient-35 years).

Alternatively, those who had low readiness in both their qualitative and RHDS data ( $n=11,35 \%)$, cited that they did not know how to care for the patient or themselves and did not feel physically well enough to be at home. A caregiver illustrated this saying:

I feel like okay, I can deal with one thing, but I don't know, like, how to change the dressing. I still have to constantly ask the nurses 'Could you please change her dressing' you know? There's not one thing where I independently do something for her so like there's nothing where I can say I independently 100 percent know how to do this and I've fully done it and I'm confident in it by myself, you know? (Female caregiver-27years)

Exploring the differences between the qualitative and RHDS data, we found participants who indicated they had low readiness in their RHDS responses but expressed higher readiness in their interviews $(n=7,23 \%)$. This sense of readiness was apparent when five out of these seven participants responded "yes" when asked directly if they felt ready to go home. One participant stated "Oh, yeah, been there and done that. I can go home" (Female patient-68 years), yet she indicated on her survey that she did not feel ready (RHDS $=5.25 / 10$ ).

Whereas those who expressed they were quantitatively ready but not qualitatively ready $(n=7,23 \%)$ emphasized both stress and uncertainty about how the process was going to occur, one stated:

It's such a stressful time, I don't remember what people say. And people give me information about what to do and where to go, and I shake my head yes, because I hear them and then $2 \mathrm{~s}$ later, I have no idea what they've said. And that's a real worry (Female caregiver-82 years).

\section{Quality of transition}

Regarding the quality of the transition, the median score for the CTM-3 was 66.7 (IQR, 33.33) with 45\% indicating they had a high-quality transition and $55 \%$ indicating they had a low-quality transition. Similarly, for the qualitative categorization, $45 \%$ experienced high-quality and $55 \%$ experienced low-quality transition, with a chance corrected Kappa score of 0.19 (95\% Cl: $-0.24,0.62)$.

Participants who had concordant high-quality transitions in both qualitative and CTM-3 data $(n=5,25 \%)$ spoke about having their healthcare needs met through receiving appropriate equipment, reassurance, and having a clear understanding of their responsibilities once they were home. One caregiver spoke about the ease of the process:

Oh [the transition] went smoothly, I was amazed. They came in, they set the bed up, it was two minutes and they were out the door. Then they brought [the patient] home, put him in bed and it was great. (Male caregiver-72years) 
For those who had a corresponding low qualitative score with a low CTM-3 score $(n=7,35 \%)$, the common challenges were a lack of clarity around responsibilities once they were home and confusion around medications. For example, the wife of a patient discussed not recognizing how much assistance her husband would need at home:

Well, I think I was totally unprepared for what in actuality happened when we got home. First of all, my husband was on a very high dose of medications and he was like almost comatose. It was like he was walking around in a trance. He couldn't do anything himself. He needed total care. All of a sudden. . . he had been doing this before he went to the hospital. He dressed himself. He showered himself. He could not do anything like that [once home]. (Female caregiver-75years)

A clear discrepancy emerged among those with low qualitative designations but high CTM-3 scores on the surveys $(n=4,20 \%)$. Patients, caregivers, or dyads expressed not having their healthcare needs met, as one participant mentioned not having appropriate equipment to support herself once home:

Well, I mean I came home weak as a kitten. . . I mean I would fall, and I would have to crawl to the nearest structure to pull myself up. (Female patient-61years)

For those who scored low on the CTM-3, but had high qualitative results $(n=4,20 \%)$ this might have been a result of changing healthcare needs the longer they were home. One participant stated this saying:

At the beginning, I had more energy and. . . I was feeling pretty good and just didn't feel like I needed the PSW, now I may change that again, because I've not felt as good. (Female patient-51years)

\section{Coping difficulty once home}

The median score for the PDCDS was 5.0 (IQR, 2.6). Survey distribution had $50 \%$ of participants indicating they had low coping difficulty and $50 \%$ high coping difficulty. Our qualitative data had $55 \%$ of participants with low coping difficulty and $45 \%$ with high coping difficulty. The discrepancies resulted in a kappa of $0.3(95 \% \mathrm{Cl}$ : -0.12 , $0.72)$.

Among participants categorized in both their quantitative and qualitative as high coping difficulty $(n=7,35 \%)$, common reasons included an inability to cope with physical side-effects, experiencing challenges managing equipment, and experiencing emotional challenges when returning home. One participant spoke about her challenges navigating at home:

Yeah, well you learn when you come home. You learn how to handle your own situation. We were not in a good position at all when we came home. Didn't know how to handle the machine, the people were inadequate. Now I'm setting up the people and we know how to handle the machine, because my husband worked it out. (Female patient-77years)

For the participants who were categorized as having low coping difficulty on both qualitative and quantitative data $(n=7,35 \%)$, key reasons were having a sense of community, feeling happy to be home, and having sufficient care providers at home. When asked about how she felt about being home, one patient stated: "Oh, I love being at home, much better than being in the hospital. You know, you sleep better. You eat better. You're around your family. .." (Female patient-72 years).

The discrepancies between the qualitative and quantitative data were among those who were designated as having high coping challenges based on the qualitative data, yet their PDCDS scores indicated low coping difficulty once home. The qualitative data suggested this was because participants experienced challenges with their physical wellbeing once home. A patient and his daughter said: 
Daughter: The first few weeks were a little bit scary because he was really weak and there are a lot of stairs in our home, in his home, and. . .

Father: And the fact that I wasn't well when I came home and I started vomiting. Everyone started. . . got a little uptight and concerned and like oh no, it's all starting again. (Male patient-58years)

Similarly, another patient discussed expectations and reality were very different, saying: "I didn't expect to come home and experience so much fatigue" (Male patient-62 years).

Among those who had high coping difficulty scores $(n=3,15 \%)$ but reported low coping challenges qualitatively, this was potentially because of the removal of the uncertainty; participants feeling like they were able to do things once they were home. For example, one patient stated:

Just not knowing what was going to happen because like I don't have bars. I don't have. . . like if I fell or something, what am I going to do? But I'm still in the stage where I'm fine, that I can do most everything and just a little help from the PSWs again for showering. They do meal prep, some cleaning. So yeah, it's a lot better than I thought it was going to be. (Female patient-51years)

\section{Discussion}

\section{Main findings}

This study examined discharge readiness, transition quality, and subsequent post-discharge coping of hospitalto-home transition in palliative care patients. Scores on the three domains provide evidence of need for attention to the hospital-to-home transition to support improved quality of care and outcomes. While there was some level of convergence of quantitative scores and qualitative representations of the transition experience, the qualitative findings also pointed to differences in how patients narrate their experiences.

\section{What this study adds?}

Using a mixed methods approach, our findings suggests that discharge readiness, quality of transition, and postdischarge coping offer valuable insight into the hospital-to-home transition. Specifically, the agreement between the qualitative and quantitative data, for both positive and challenging transitions, suggests areas that are clearly important to palliative care patients/caregivers in transitions, above and beyond utilization and readmission concerns. Whereas the discrepancies indicate areas for future examination. Interestingly, the scores showed lower readiness ${ }^{35,36}$ and transition quality, ${ }^{37-39}$ and poorer coping difficulty, ${ }^{40,41}$ pointing to the challenges of transitions for palliative care patients and opportunities to improve the transition experience for these patients.

Participants who were ready to go home highlighted the importance of community support upon returning home; whereas those not ready cited feelings of uncertainty and stress. Findings are well-supported by an existing concept analysis review ${ }^{42}$ that found community support contributes to a sense of discharge safety. What is more challenging, and an insight from this study, is meeting the needs of those who express readiness to go home, yet are primarily motivated by a desire to leave the hospital and may not be adequately prepared to transition home. This is concerning because older adults who feel unsupported in the transition process may disengage from the process altogether, leading to a worse transition. ${ }^{43}$ Discerning the difference between eagerness and readiness may be challenging, yet it is critically important to promote readiness for discharge.

Those who experienced a high-quality transition, as per the concordant data, felt they had reassurance and support, their equipment needs met, and a clear understanding of their responsibilities at home. Those who had concordant low-quality transitions had poor understanding of their responsibilities and experienced confusion with their medications. These findings align with other studies examining transitions of care in older adults and 
general inpatients. ${ }^{1-4}$ Qualitatively, participants recalled their healthcare needs not being met and confusion around medication, but quantitatively their responses suggested the opposite. Within palliative care, healthcare needs may be more nebulous and change more rapidly than other populations. ${ }^{44} \mathrm{As}$ a result, it may be challenging for patients and caregivers to articulate their needs as they move from hospital-to-home. The gap between the level of support in hospital and expected independence at home is clearly challenging to navigate for patients and has been documented in past studies. ${ }^{2,45}$ Finding ways to help caregivers and patients better understand their needs and how to meet them is imperative.

Examining post-discharge coping difficulty, participants with little difficulty identified having community and healthcare provider support and were happy to be at home. In contrast, those with high difficulty mentioned their physical symptoms, challenges with equipment, and emotional distress. Practical findings are wellsubstantiated in previous literature, with caregivers citing difficulty caring for unwell patients and frustrations with equipment. ${ }^{46}$ Participants with conflicting qualitative and quantitative data discussed emotional distress due to holding expectations in the hospital that they would manage well once home, yet not having that capacity once home. Dose et al., ${ }^{47}$ found similar results, with patients feeling an "unexpected disruption" upon experiencing a different reality than expected when receiving hospice-at-home. Our study builds on this, as participants experiencing little difficulty do not express feeling the same emotional distress. It may be beneficial to set clear expectations that hospital discharge does not imply a pre-hospitalization capacity, but rather that patients no longer need acute levels of care.

\section{Limitations}

The limited number of individuals completing Visit 2 may have impacted our ability to detect changes. Only $57 \%$ of approached individuals consented to participate and our participants' scores were very similar, suggesting a homogenous sample that may trend toward those who were less ill. Regarding outcomes, these scales are all self-reported and using the median to dichotomize scores may have created an artifactual threshold contributing to the low concordance. Merging the experiences of patients and caregivers helps to focus on the transition as a joint patient/caregiver experience, but the caregiver experiences may have been overshadowed due to large numbers of patients included. Conducting the scales first and focusing on three domains may have inhibited emergences of other domains important to palliative care patients. Finally, the RHD scale was administered up to 4 days before discharge, potentially impacting readiness since readiness increases the closer the patient gets to discharge.

\section{Conclusions and implications}

Integrating qualitative and quantitative data provided overlapping but distinct perspectives into the experience of discharge readiness, quality, and post-discharge coping. Concordant data should be used to support an intervention targeted toward these domains that is tailored to a palliative care population's need within a transition. Discrepancies should be considered areas to examine further in future studies examining hospital-tohome transitions. Given our findings, future research should validate these scales in a palliative population to ensure patients' voices are heard throughout the course of the transition.

\section{Acknowledgements}

This work was completed while Stephanie Saunders and Sarina Isenberg were affiliated with the Temmy Latner Centre for Palliative Care, part of Sinai Health in Toronto Ontario.

We would like to thank our colleagues at Toronto General Hospital and Temmy Latner Centre for Palliative Care, part of Sinai Health in Toronto, CA. 


\section{Authors' contributions}

Stephanie Saunders conceptualized the study and study design, participated in acquiring the data, led the analysis and interpretation of the data, drafted the first version of the manuscript, and led final edits and revisions. Marianne E. Weiss developed the instruments used in the data collection, supported the analysis and interpretation of the data, and critically reviewed drafts of the manuscript Christopher Meaney conducted the analysis and helped with interpretation of the data, and critically reviewed drafts of the manuscript. Tieghan Killackey conducted the analysis and interpretation of the data, and critically reviewed drafts of the manuscript. Jaymie Varenbut participated in acquiring the data and critically reviewed drafts of the manuscript. Emily Lovrics helped to conceptualize the study, assisted in acquiring the data, helped with the analysis and interpretation of the data, and critically reviewed drafts of the manuscript. Natalie Ernecoff supported the analysis and interpretation of the data, and critically reviewed drafts of the manuscript. Amy T Hsu supported the analysis and interpretation of the data, and critically reviewed drafts of the manuscript. Maya Stern helped to conceptualize the study, assisted in acquiring the data, helped with the analysis and interpretation of the data, and critically reviewed drafts of the manuscript. Ramona

Mahtani helped to conceptualize the study, assisted in acquiring the data, helped with the analysis and interpretation of the data, and critically reviewed drafts of the manuscript. Kirsten Wentlandt helped to conceptualize the study, assisted in acquiring the data, helped with the analysis and interpretation of the data, and critically reviewed drafts of the manuscript. Sarina $\mathbf{R}$ Isenberg conceptualized the study, assisted in acquiring the data, led the analysis and interpretation of the data, and critically reviewed drafts of the manuscript.

\section{Declaration of conflicting interests}

The author(s) declared no potential conflicts of interest with respect to the research, authorship, and/or publication of this article.

\section{Funding}

The author(s) disclosed receipt of the following financial support for the research, authorship, and/or publication of this article: This work was supported by the Temmy Latner Centre for Palliative Care's Golda Fine Award; the University of Toronto's Department of Family and Community Medicine Cass Family Grant for Catalyzing Change.

\section{Statement about data}

Data is unavailable for confidentiality reasons and small sample size. For questions regarding data please contact the corresponding author.

\section{References}

1. Snow, V, Beck, D, Budnitz, T, et al Transitions of care consensus policy statement: American College of Physicians, Society of General Internal Medicine, Society of Hospital Medicine, American Geriatrics Society, American College of Emergency Physicians, and Society for Academic Emergency Medicine. J Hosp Med 2009; 4(6): 364-370.

2. Coleman, EA, Boult, C; American Geriatrics Society Health Care Systems Committee . Improving the quality of transitional care for person with complex care needs. J Am Geriatr Soc 2003; 51(4): 556-557.

3. Jeffs, L, Kitto, S, Merkley, J, et al Safety threats and opportunities to improve interfacility care transitions: insights from patients and family members. Patient Prefer Adherence 2012; 6: 711-718.

4. Naylor, MD, Aiken, LH, Kurtzman, ET, et al The care span: the importance of transitional care in achieving health reform. Health Affairs 2011; 30(4): 746-754. 
5. Adams, K, Greiner, AC, Corrigan, JM. Committee on the crossing the quality chasm: next steps toward a new health care system [press release]. Washington, DC: National Academies Press, 2004.

6. van Melle, MA, van Stel, HF, Poldervaart, JM, et al Measurement tools and outcome measures used in transitional patient safety: a systematic review. PLoS One 2018; 13(6): e0197312.

7. $\mathrm{ClHI}$. Patient rerported outcome measures: $\mathrm{ClHI}$ 's PROMs Program 2019, https://www.cihi.ca/sites/default/files/document/patient-reported-outcome-measures-promsinfosheet-may2019-en-web.pdf (accessed 10 September 2020).

8. Hesselink, G, Schoonhoven, L, Barach, P, et al Improving patient handovers from hospital to primary care: a systematic review. Ann Intern Med 2012; 157(6): 417-428.

9. Haggerty, JL, Roberge, D, Freeman, GK, et al Validation of a generic measure of continuity of care: when patients encounter several clinicians. Ann Fam Med 2012; 10(5): 443-451.

10. D'Angelo, D, Mastroianni, C, Artico, M, et al Validity and reliability of the Palliative Care Transition Measure for Caregivers (PCTM-C). Palliat Support Care 2019; 17(2): 202-207.

11. Allen, J, Hutchinson, AM, Brown, R, et al User experience and care integration in transitional care for older people from hospital to home: a meta-synthesis. Qual Health Res 2017; 27(1): 24-36.

12. Uijen, AA, Schellevis, FG, van den Bosch, WJ, et al Nijmegen Continuity Questionnaire: development and testing of a questionnaire that measures continuity of care. J Clin Epidemiol 2011; 64(12): 1391-1399.

13. Weiss, M, Piacentine, LB. Psychometric properties of the readiness for hospital discharge scale. J Nurs Meas 2006; 14(3): 163-180.

14. Saunders, S, Killackey, T, Kurahashi, A, et al Palliative care transitions from acute care to communitybased care-a systematic review. J Pain Symptom Manage 2019; 58: 721-734.e1.

15. Scott, M, Shaver, N, Lapenskie, J, et al Does inpatient palliative care consultation impact outcomes following hospital discharge? A narrative systematic review. Palliat Med 2020; 34(1): 5-15.

16. Morey, $T$, Scott, M, Saunders, S, et al Transitioning from hospital to palliative care at home: patient and caregiver perceptions of continuity of care. J Pain Symptom Manage. Epub ahead of print 29 December 2020. DOI: 10.1016/j.jpainsymman.2020.12.019.

17. Killackey, T, Lovrics, E, Saunders, S, et al Palliative care transitions from acute care to community-based care: a qualitative systematic review of the experiences and perspectives of health care providers. Palliat Med 2020; 34(10): 1316-1331.

18. Wilson, DM, Birch, S. A scoping review of research to assess the frequency, types, and reasons for endof-life care setting transitions. Scand J Public Health 2020; 48(4): 376-381.

19. Gomes, B, Calanzani, N, Gysels, M, et al Heterogeneity and changes in preferences for dying at home: a systematic review. BMC Palliat Care 2013; 12(1): 1-13.

20. Higginson, IJ, Sen-Gupta, G. Place of care in advanced cancer: a qualitative systematic literature review of patient preferences. J Palliat Med 2000; 3(3): 287-300.

21. Howell, D, Wang, H, Roman, E, et al Preferred and actual place of death in haematological malignancy. BMJ Support Palliat Care 2017; 7(2): 150-157.

22. Waghorn, $M$, Young, $H$, Davies, A. Opinions of patients with cancer on the relative importance of place of death in the context of a 'good death'. BMJ Support Palliat Care 2011; 1(3): 310-314.

23. Coleman, EA, Smith, JD, Frank, JC, et al Development and testing of a measure designed to assess the quality of care transitions. Int J Integr Care 2002;2:e02.

24. Weiss, ME, Costa, LL, Yakusheva, O, et al Validation of patient and nurse short forms of the Readiness for Hospital Discharge Scale and their relationship to return to the hospital. Health Serv Res 2014; 49(1): 304.

25. Creswell, JW, Plano Clark, VL. Designing and conducting mixed methods research. Los Angeles, CA: Sage Publications, 2017.

26. Creswell, JW, Poth, CN. Qualitative inquiry and research design: choosing among five approaches. Los Angeles, CA: Sage Publications, 2016. 
27. Ryan, A. Post-positivist approaches to research In: Researching and writing your thesis: a guide for postgraduate students. Maynooth, IE: Maynooth Adult and Community Education (MACE), 2006, pp.1226.

28. Albright, $\mathrm{K}$, Gechter, $\mathrm{K}, \mathrm{Kempe}, \mathrm{A}$. Importance of mixed methods in pragmatic trials and dissemination and implementation research. Acad Pediatr 2013; 13(5): 400-407.

29. Zimmermann, C, Burman, D, Bandukwala, S, et al Nurse and physician inter-rater agreement of three performance status measures in palliative care outpatients. Support Care Cancer 2010; 18(5): 609-616.

30. Parry, C, Mahoney, E, Chalmers, SA, et al Assessing the quality of transitional care: further applications of the care transitions measure. Med Care 2008; 46(3): 317-322.

31. Isenberg, S, Killackey, T, Saunders, S, et al Going home [is] just a feel-good idea with no structure: a qualitative exploration of patient and family caregiver needs when transitioning from hospital to home in palliative care. J Pain Symptom Manage. Epub ahead of print 22 February 2021. DOI: 10.1016/j.jpainsymman.2021.02.026.

32. MAXQDA . Version 18. MAXQDA, software for qualitative data analysis. Berlin, Germany: Sozialforschung $\mathrm{GmbH}, 2018$.

33. Creswell, JW, Klassen, AC, Plano Clark, VL, et al Best practices for mixed methods research in the health sciences. Vol. 2013. Bethesda, MD: National Institutes of Health, 2011, pp. 541-545.

34. Landis, JR, Koch, GG. The measurement of observer agreement for categorical data. Biometrics 1977; 33(1): 159-174.

35. Weiss, M, Yakusheva, O, Bobay, $\mathrm{K}$, et al Effect of implementing discharge readiness assessment in adult medical-surgical units on 30-day return to hospital: the READI randomized clinical trial. JAMA Netw Open 2019; 2(1): e187387.

36. Weiss, M, Yakusheva, O, Bobay, K. Nurse and patient perceptions of discharge readiness in relation to postdischarge utilization. Med Care 2010; 48(5): 482-486.

37. Record, JD, Niranjan-Azadi, A, Christmas, C, et al Telephone calls to patients after discharge from the hospital: an important part of transitions of care. Med Educ Online 2015; 20(1): 26701.

38. Sabbatini, AK, Gallahue, F, Newson, J, et al Capturing emergency department discharge quality with the care transitions measure: a pilot study. Acad Emerg Med 2019; 26: 605-609.

39. Soong, C, Kurabi, B, Wells, D, et al Do post discharge phone calls improve care transitions? A clusterrandomized trial. PLoS One 2014; 9(11): e112230.

40. Miller, JF, Piacentine, LB, Weiss, M. Coping difficulties after hospitalization. Clin Nurs Res 2008; 17(4): 278-296.

41. Weiss, M, Sawin, K, Gralton, K, et al Discharge teaching, readiness for discharge, and post-discharge outcomes in parents of hospitalized children. J Pediatr Nurs 2017; 34: 58-64.

42. Galvin, EC, Wills, T, Coffey, A. Readiness for hospital discharge: a concept analysis. J Adv Nurs 2017; 73(11): 2547-2557.

43. Rydeman, I, Törnkvist, L. Getting prepared for life at home in the discharge process-from the perspective of the older persons and their relatives. Int J Older People Nurs 2010; 5(4): 254-264.

44. O'Leary, N, Murphy, NF, O'Loughlin, C, et al A comparative study of the palliative care needs of heart failure and cancer patients. Eur J Heart Fail 2009; 11(4): 406-412.

45. Wilson, DM, Birch, S. Moving from place to place in the last year of life: a qualitative study identifying care setting transition issues and solutions in Ontario. Health Soc Care Community 2018; 26(2): 232-239.

46. Henriksson, A, Årestedt, K. Exploring factors and caregiver outcomes associated with feelings of preparedness for caregiving in family caregivers in palliative care: a correlational, cross-sectional study. Palliat Med 2013; 27(7): 639-646.

47. Dose, $A M$, Rhudy, LM, Holland, DE, et al The experience of transition from hospital to home hospice: unexpected disruption. J Hosp Palliat Nurs 2011; 13(6): 394-402. 